\title{
Double blind trial of bezafibrate in familial hypercholesterolaemia
}

\author{
K A H WHEELER, R J WEST, J K LLOYD, AND J BARLEY \\ Department of Child Health, St George's Hospital Medical School, London
}

SUMmARY A six month, double blind, crossover controlled trial of bezafibrate was conducted in 14 children with familial hypercholesterolaemia all of whom had a strong family history of early coronary heart disease. The bezafibrate was given twice daily in a dose of 10 to $20 \mathrm{mg} / \mathrm{kg} / \mathrm{day}$. The mean plasma total cholesterol concentration on bezafibrate was $22 \%$ lower than during the period on placebo and there was a moderate rise in high density lipoprotein cholesterol. Bezafibrate may be a useful adjunct to treatment in these children.

In the dominantly inherited condition of familial hypercholesterolaemia the risk of premature coronary heart disease is very high. ${ }^{1}$ Reducing very high plasma concentrations of cholesterol (and low density lipoprotein) in middle aged men has been shown to lower the incidence of coronary heart disease. ${ }^{2}$ To delay attempts at lowering lipids until middle age in this disorder will be too late for many patients, and it is expected that treatment will be of maximum benefit if started in childhood and continued throughout life. ${ }^{3}$

Dietary treatment alone is insufficient to achieve normal plasma cholesterol concentrations in some children with familial hypercholesterolaemia, and in the long term is ineffective in most because of poor compliance. ${ }^{4}$ Cholestyramine is currently the drug of choice when additional treatment is required but we have shown that by the end of 8 years slightly less than half the children will still be taking this unpalatable drug. ${ }^{5}$ Other drugs, therefore, require evaluation in childhood.

Bezafibrate, an analogue of clofibrate, has been extensively used in the treatment of adults with various types of hyperlipoproteinaemia and has been shown to be effective in type IIa hyperlipoproteinaemia (the pattern in familial hypercholesterolaemia) in which it lowers both cholesterol and triglyceride concentrations. ${ }^{6}$ It has been well tolerated in adults without evidence of undesirable side effects for periods up to two years, and no evidence of long term toxicity has been found in studies in animals. ${ }^{7}$ Bezafibrate may, therefore, be a potentially useful drug for children with familial hypercholesterolaemia and we report the results of a double blind controlled study in children with this disorder.

\section{Patients and methods}

Fourteen children with heterozygous familial hypercholesterolaemia (eight girls and six boys, age range 4 to 15 years and including four sibling pairs) completed a six month, double blind crossover trial of bezafibrate and placebo. The diagnosis of familial hypercholesterolaemia had been established by finding a plasma total cholesterol concentration greater than $6.7 \mathrm{mmol} / \mathrm{l}(269 \mathrm{mg} / 100 \mathrm{ml})$ (the value found to result in minimal misclassification $\left.{ }^{8}\right)$, a type IIa pattern on lipoprotein electrophoresis, and normal fasting triglyceride (less than $1.5 \mathrm{mmol} / \mathrm{l}^{9}$ ) in the patient, with either similar lipoprotein abnormalities in one of the parents, or where a parent had died of premature coronary heart disease, a similar lipid abnormality in another close relative.

Before the trial all children had been treated by dietary measures (low saturated fat and increased polyunsaturated fat) which had proved inadequate to control plasma cholesterol concentrations, and they had therefore been given cholestyramine. All had refused to continue taking this drug after variable periods, and for at least three months before entry to the trial none had had any hypolipidaemic drug, and plasma cholesterol concentrations were unacceptably high (Table). Although most children were still alleged by their parents to be taking a fat restricted diet, assessment by a dietitian indicated a mean total fat intake of $98 \mathrm{~g} /$ day (range 44 to $148 \mathrm{~g}$ ). During the trial period the patients were asked not to change their diets but repeat assessments were not undertaken.

The trial had ethical committee approval, and informed consent was obtained. Active and placebo tablets were provided-the active tablets containing 


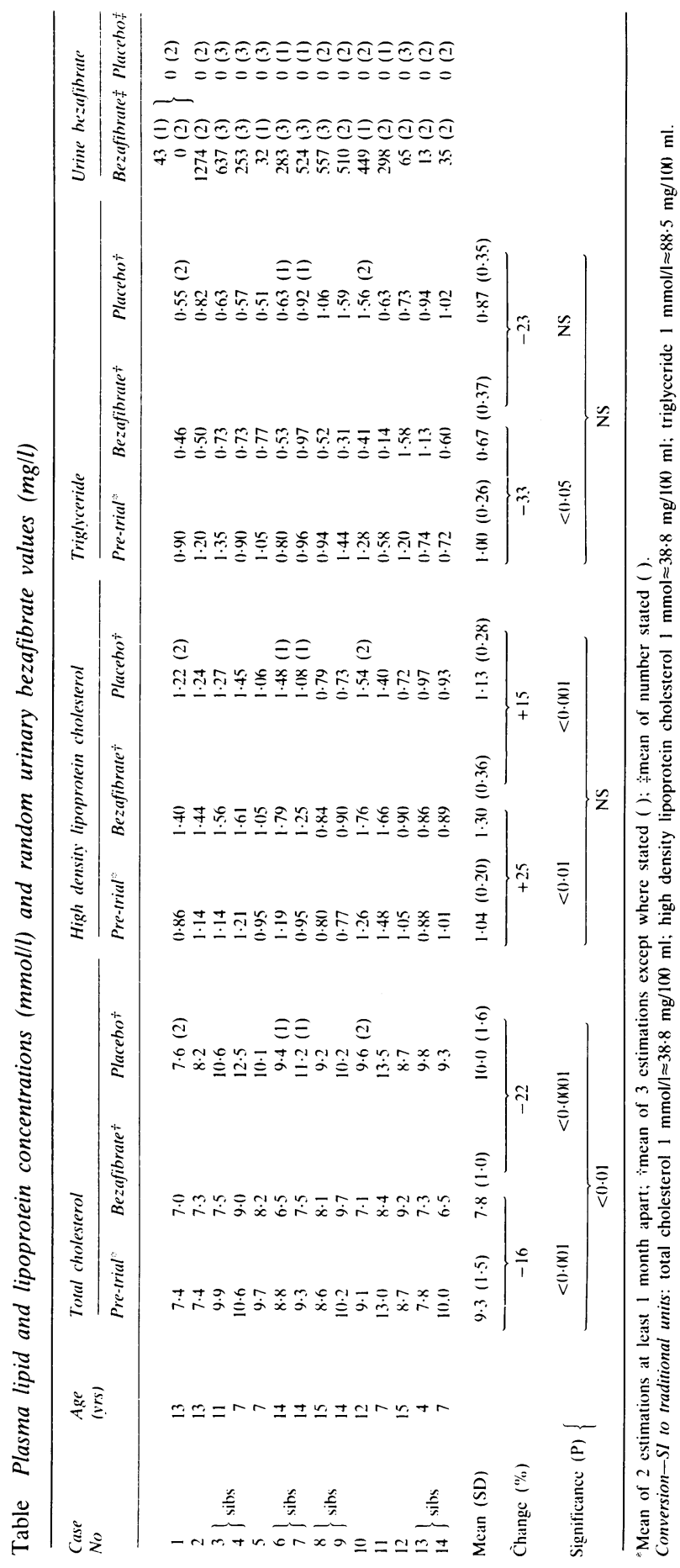


$100 \mathrm{mg}$ bezafibrate. The dose of bezafibrate was 10 to $20 \mathrm{mg} / \mathrm{kg} /$ day given twice daily. The hospital pharmacist was responsible for randomly allocating the active (bezafibrate) tablets to either the first or second three month period; when there were two children in a family in the trial identical prescriptions were given to both to obviate the chance of confusion.

Blood was obtained in the fasting state at the beginning and at monthly intervals throughout the trial. Plasma total cholesterol, triglyceride, high density lipoprotein cholesterol, urea, bilirubin, electrolytes, calcium, alkaline phosphatase, and alanine transaminase, haemoglobin, white blood cell count, and platelets were measured at each visit. Random urine samples were collected each month, stored frozen and subsequently analysed for bezafibrate. At each visit a limited clinical examination was conducted and enquiries made about general health, possible side effects, and compliance with taking the tablets. No formal attempt was made to count the number of tablets taken.

Statistical analysis was carried out using a paired Student's $t$ test.

\section{Results}

Plasma total cholesterol. At entry to the trial plasma total cholesterol varied between 7.1 and $13.5 \mathrm{mmol} / \mathrm{l}$ $(275$ and $523 \mathrm{mg} / 100 \mathrm{ml})$. For individual patients the values were similar to those obtained at least one month before the trial, indicating a stable state. For subsequent analyses the mean of the two pre-trial values has been used (Table). Analysis of the results during the placebo and bezafibrate periods showed that any change had occurred within the first month and there was no consistent drift thereafter. Mean values for the two periods are therefore presented (Table). Overall the plasma cholesterol concentrations were significantly higher during the placebo period than in the period before the trial, and this was irrespective of whether placebo or bezafibrate was given first. Mean plasma total cholesterol while on bezafibrate was $22 \%$ lower than during the placebo period and $16 \%$ lower than in the period before the trial. The results for individual children show that the reduction in plasma cholesterol concentration on bezafibrate was more than $10 \%$ (compared with placebo values) in 11; only one patient showed a rise in total cholesterol (of 6\%) during bezafibrate treatment.

Plasma high density lipoprotein cholesterol. Values before the trial were within normal limits. ${ }^{9}$ There was a mean rise in high density lipoprotein cholesterol on bezafibrate of $15 \%$ compared with placebo values ( $25 \%$ compared to pre-trial values) (Table).

Plasma triglyceride. Values before the trial were within normal limits. ${ }^{9}$ Although there was a mean fall of plasma triglyceride on bezafibrate treatment of $23 \%$ when compared with placebo values $(33 \%$ compared with pre-trial values) this did not reach statistical significance; in six children concentrations rose (compared with placebo), and in the remainder the fall varied between 16 and $78 \%$.

Urine bezafibrate. Although urine bezafibrate values are expressed in $\mathrm{mg} / \mathrm{l}$ as a mean of the number of samples received, timed collections were not obtained and the concentration in individual specimens cannot be taken as any indication of the degree of compliance with treatment. Nevertheless it is gratifying that all except one patient (case 1) were excreting bezafibrate in all samples of urine analysed during the active drug period and that no bezafibrate was detected in any sample collected during the placebo period. The patient in case 1 had no bezafibrate in his urine on two occasions during the active drug period, and it is noteworthy that it was only on the occasion when his urine contained bezafibrate that his plasma total cholesterol concentration was lower than the pre-trial or placebo period-6.09 mmol/l $(236 \mathrm{mg} / 100 \mathrm{ml})$ compared with 7.4 and $7.6 \mathrm{mmol} / \mathrm{l}(287$ and $294 \mathrm{mg} / 100 \mathrm{ml})$ respectively.

Other findings. In one child plasma alkaline phosphatase activity was high at the end of the third month on bezafibrate. At the time he had a mild intercurrent infection and values subsequently returned to normal. In another child there was a slight transient rise in alanine transaminase during the first two months on bezafibrate but values were normal at the end of the third month. In all other children, blood counts, liver function tests, and plasma electrolytes were normal. Growth was satisfactory throughout the trial and there were no reported clinical side effects. All children declared a strong preference for the tablets compared with their previous treatment with a resin.

\section{Discussion}

The mean reduction of plasma total cholesterol in the children in the present study $(22 \%)$ is similar to that reported in adult studies, as is the rise in high density lipoprotein cholesterol $(15 \%){ }^{6}{ }^{10}$ There was considerable variation, however, in the response between individual patients, some showing little or no reduction in total cholesterol whereas others 
showed a very considerable fall. The degree of response to bezafibrate could not be predicted by the initial values of total cholesterol before the trial, and in only one patient (case 1) is there evidence that non-compliance with drug treatment may have been responsible for a relatively poor response.

The significantly higher mean total plasma cholesterol concentrations in the placebo period compared with the period before the trial cannot be explained. It is possible that there was some relaxation in the dietary regimen once the patients thought they were having alternative treatment; as dietary assessments were not repeated during the trial this cannot be confirmed. There was no correlation between the pre-trial fat intake and plasma cholesterol concentrations, nor did pre-trial fat intake correlate with the degree of change in either the bezafibrate or placebo period.

The dietary assessment carried out before the trial clearly indicated that few, if any, of the patients were complying with the degree of fat restriction advised and the efficacy of bezafibrate in our study must be judged against this background of a relatively high total fat intake; better results might well have been achieved had fat intake been lower, but as long term compliance with diet is so poor in children ${ }^{4}$ the present results are more indicative of what is likely to be achieved with continuation of bezafibrate treatment in the long term.

No clinical side effects attributable to bezafibrate occurred during the short period of study, and all children volunteered that they preferred taking bezafibrate tablets to cholestyramine. In view of the transient rise in plasma alkaline phosphatase in one patient (possibly attributable to an intercurrent illness) and in alanine transaminase (unexplained) in another patient, regular monitoring of liver function should probably be undertaken in any children on long term treatment.

In conclusion, our study has shown that bezafibrate can result in useful lowering of the plasma total cholesterol concentration, coupled with a moderate rise in the plasma high density lipoprotein cholesterol concentration, in children with familial hypercholesterolaemia. Because the long term safety of this drug has not yet been established in prospective trials in adults we would not recommend it for the initial treatment of children with familial hypercholesterolaemia. Nevertheless, for those children who cannot take cholestyramine, and whose risk of early coronary heart disease is high as judged by family history, it may have a useful role to play in treatment, though careful monitoring will be required.

We thank consultant colleagues for referring patients and the staff pharmacists at St George's Hospital, and Dr P D Lang of MCP Pharmaceuticals for practical help.

\section{References}

1 Goldstein JL, Brown MS. Familial hypercholesterolaemia. In: Stanbury JB, Wyngaarden JB, Fredrickson DS, Goldstein JL, Brown MS, eds. The metabolic basis of inherited disease. 5th ed. New York: McGraw-Hill, 1983:672-712.

2 Lipid Research Clinics Program. The Lipid Research Clinics Coronary Primary Prevention Trial Results. I. Reduction in incidence of coronary heart disease. JAMA 1984;251:351-61.

3 West RJ, Lloyd JK. Hypercholesterolaemia in childhood. $A d v$ Pediatr 1979;26:1-34

${ }^{4}$ West RJ, Fosbrooke AS, Lloyd JK. Treatment of children with familial hypercholesterolaemia. Postgrad Med J 1975;51: (Suppl 8):82-6.

5 West RJ, Lloyd JK, Leonard JV. Long-term follow-up of children with familial hypercholesterolaemia treated with cholestyramine. Lancet 1980;ii:873-5.

${ }^{6}$ Olsson AG. Effect of bezafibrate on lipids and lipoproteins in patients with hyperlipoproteinaemia Type IIa and IV on long-term treatment. Lipoproteins and coronary heart disease. New York: Witzstroch Publishing House, 1980:170-1.

7 Hebold G, Czerwek H, Hartrig F, Sterz H, Grafe A, Bleuel H. Toxicological, teratological, fertility, mutagenicity, and carcinogenicity investigations in bezafibrate in animals. Lipoproteins and coronary heart disease. New York: Witzstroch Publishing House, 1980:61-3.

${ }^{8}$ Leonard JV, Whitelaw AGL, Wolff OH, Lloyd JK, Slack J. Diagnosing familial hypercholesterolaemia in childhood by measuring serum cholesterol. Br Med J 1977;i:1566-8.

9 Lloyd JK. Plasma lipid disorders. In: Clayton BE, Round JM, eds. Chemical pathology and the sick child. Oxford: Blackwell Scientific Publications, 1984:245-64.

${ }^{10}$ Mordasini R, Riesen W, Oster P, Keller M, Middelhoff G, Lang PD. Reduced LDL and increased HDL-apoproteins in patients with hypercholesterolaemia under treatment with bezafibrate. Atherosclerosis 1981;40:153-8.

Correspondence to Professor J K Lloyd, St George's Hospital Medical School, Cranmer Terrace, London SW17 ORE.

Received 12 September 1984 